\title{
Review on major pests of mulberry and its management protocol
}

\author{
Y. T. Jadhav*, V. Venkatesh and N. Deekshitha \\ Department of Agricultural Entomology, Ratnai College of Agriculture, Akluj, Solapur (M.S.) India
}

\section{ARITCLE INFO \\ Received : 11.01 .2019 \\ Accepted : 23.03.2019}

\section{KEY WORDS :}

Mulberry, Management, Silkworm, Symptom, Pest, Integrated, Bio-control
*Corresponding author:

Email : rupayogeshjadhav@ gmail.com

\begin{abstract}
Sericulture is an emerging agro-based enterprise for small and marginal holding farmers having less capital investment. This enterprise involves two distinct activities viz., silkworm rearing and another important one is mulberry leaf production which decides productivity and profitability in sericulture. Mulberry plant have been found attacked by some major pests along with some natural enemies been observed in this locality. This results in severe economical losses to the sericulture farmers. Considering the farmers interest in adopting chemical measures in controlling the mulberry pests is affecting the silkworm rearing to large extent. Hence, a specific study on pest, seasonal attack, symptoms caused, their characteristic alongwith integrated management approach with special emphasis on bio-control measures needs to be popularized among farmers by intensified extension efforts.
\end{abstract}

How to view point the article : Jadhav, Y.T., Venkatesh, V. and Deekshitha, N. (2019). Review on major pests of mulberry and its management protocol. Internat. J. Plant Protec., 12 (1) : 77 80, DOI : 10.15740/HAS/IJPP/12.1/77-80, Copyright@ 2019: Hind Agri-Horticultural Society. 